Gut, 1967, 8, 242

\title{
Comparison of the effects of a gastrin extract and a synthetic pentapeptide on gastrointestinal motility in the cat
}

\author{
JULIAN NEELY \\ From the Surgical Professorial Unit, St. Bartholomew's Hospital, London
}

EDITORIAL COMMENT Gastrin (Leo) produced motility effects in the small intestine and colon but I.C.I. 50,123 failed to produce a motility response in the small intestine.

Gastrin was extracted by Gregory and Tracy in 1959 and was found to consist of two almost identical polypeptides which they termed gastrin I and gastrin II. The same workers later showed that the terminal tetrapeptide had most, if not all, of the physiological properties of gastrin and that gastrinlike peptides having the terminal tetrapeptide were physiologically active (Tracy and Gregory, 1964). Considerable interest has been shown in the effects of these substances on gastrointestinal motility. Blair, Harper, Lake, Reed, and Scratcherd (1961) studied the motility effects of their extract of gastric antral mucosa on the alimentary tract of the cat, and Tracy and Gregory (1964) have compared the effects of gastrin and the gastrin-like peptides on the stomach and small bowel of dogs. Studies on gastrointestinal motility in man have been carried out by Smith and Hogg (1966) using gastrin II and by Logan and Connell (1966) using I.C.I. 50,123, a synthetic pentapeptide containing the terminal gastrin tetrapeptide. However, there is some lack of agreement in the results obtained by the above investigators and it was considered worthwhile to compare the motility effects of a gastrin extract (Leo) with those of a synthetic polypeptide (I.C.I. 50,123) on all parts of the alimentary tract of the cat.

The mode of action of gastrin is uncertain. Bennett (1965), from his studies in vitro, has suggested that gastrin acts by releasing acetylcholine from the post-ganglionic parasympathetic nerves but Blair and his colleagues (1961) found that the motility effects of gastrin in the cat persisted after atropinization. The effects of atropine on the action of gastrin and I.C.I. 50,123 have therefore been examined in this study.

The extrinsic control of alimentary motility is mediated through the sympathetic and para- sympathetic nervous systems and these two systems may be viewed as physiological antagonists (Koelle, 1965). The current concept is that the parasympathetic nervous system controls the motor drive of gastrointestinal activity and the sympathetic nervous system conveys inhibitory impulses to the gut. Any motor effects would therefore be augmented by blockade of the sympathetic nervous system. As there is evidence that there is a degree of sympathetic inhibition of intestinal motility in the recently laparotomized animal (Neely and Catchpole, 1967), the effect of gastrin and of I.C.I. 50,123 has been studied in these experiments both before and after sympathetic blockade.

\section{METHOD}

The preparation used in these experiments has been described in full elsewhere (Neely and Catchpole, 1967). Briefly, it consisted of a cat, anaesthetized with chloraloseurethane mixture, with the anterior abdominal wall replaced by a transparent nylon window. Motility was recorded by a small latex balloon in the stomach and open-ended fluid-filled tubes in the small intestine and colon; a catheter was also placed in a femoral artery to monitor arterial pressure. These cannulae were connected via strain-gauge pressure transducers to a multichannel recorder. Body temperature was monitored by a rectal thermometer and heat was supplied by a warmed table and radiant lamp as necessary. Motility was assessed both from visual observations and from recorded activity, having regard to amplitude and duration of the activity.

The gastrin extract used was supplied by Leo Pharmaceuticals, Denmark, and was given in doses of 5 Leo units $/ \mathrm{kg}$. body weight or in 10 Leo units $/ \mathrm{kg}$. if the former dose did not have any effect on motility. All the gastrin extract used was from the same batch. The synthetic pentapeptide I.C.I. 50,123 was used in doses of $1 \mu \mathrm{g} . / \mathrm{kg}$. body weight, or $2 \mu \mathrm{g} . / \mathrm{kg}$. if the lesser dose had not had any effect on motility. 
TABLE I

DRUGS USED IN THESE EXPERIMENTS, THEIR DOSAGE, AND AN INDICATION OF THEIR ACTIONS

Dose (mg./kg.)

2

Phenoxybenzamine

Propranolol

Guanethidine

Atropine

The drugs used in this study, their dosage, and an indication of their actions, are shown in Table I. The doses are those recommended for laboratory animals and the degree of blockade obtained has been discussed previously (Neely and Catchpole, 1967). All the drugs were injected intravenously; gastrin and I.C.I. 50,123 were given over a period of approximately one minute and the sympathetic blocking drugs were infused slowly using a power-driven syringe. The dose of gastrin or I.C.I. 50,123 required to produce motility was determined in each preparation and the same dosage was used throughout that experiment. In the occasional animal in which no motility was obtained in the initial preparation the hormone was repeated following sympathetic blockade. Sympathetic blockade was obtained by two methods either by a combination of phenoxybenzamine and propranolol given successively or by guanethidine and propranolol. The effects of gastrin and I.C.I. 50,123 were also studied following $\alpha$-adrenergic blockade, $\beta$-adrenergic
Sympathetic

$\alpha$

Block

Block

Block

Block

Block

blockade, atropine and mepyramine maleate, an antihistamine given in a dose of $1 \mathrm{mg} . / \mathrm{kg}$. body weight.

\section{RESULTS}

The data from experiments on 14 cats are available for study.

GASTRIN (LEO) The effects of this hormone on gastrointestinal motility were studied in 10 cats and the results are summarized in Table II. The motility responses to gastrin in the initial preparation were of a similar magnitude in the small intestine and colon but the response of the stomach was minimal (Fig. 1, Table II); $\alpha$-adrenergic blockade potentiated the effect of gastrin on the small intestine but the responses of the stomach and colon were unchanged
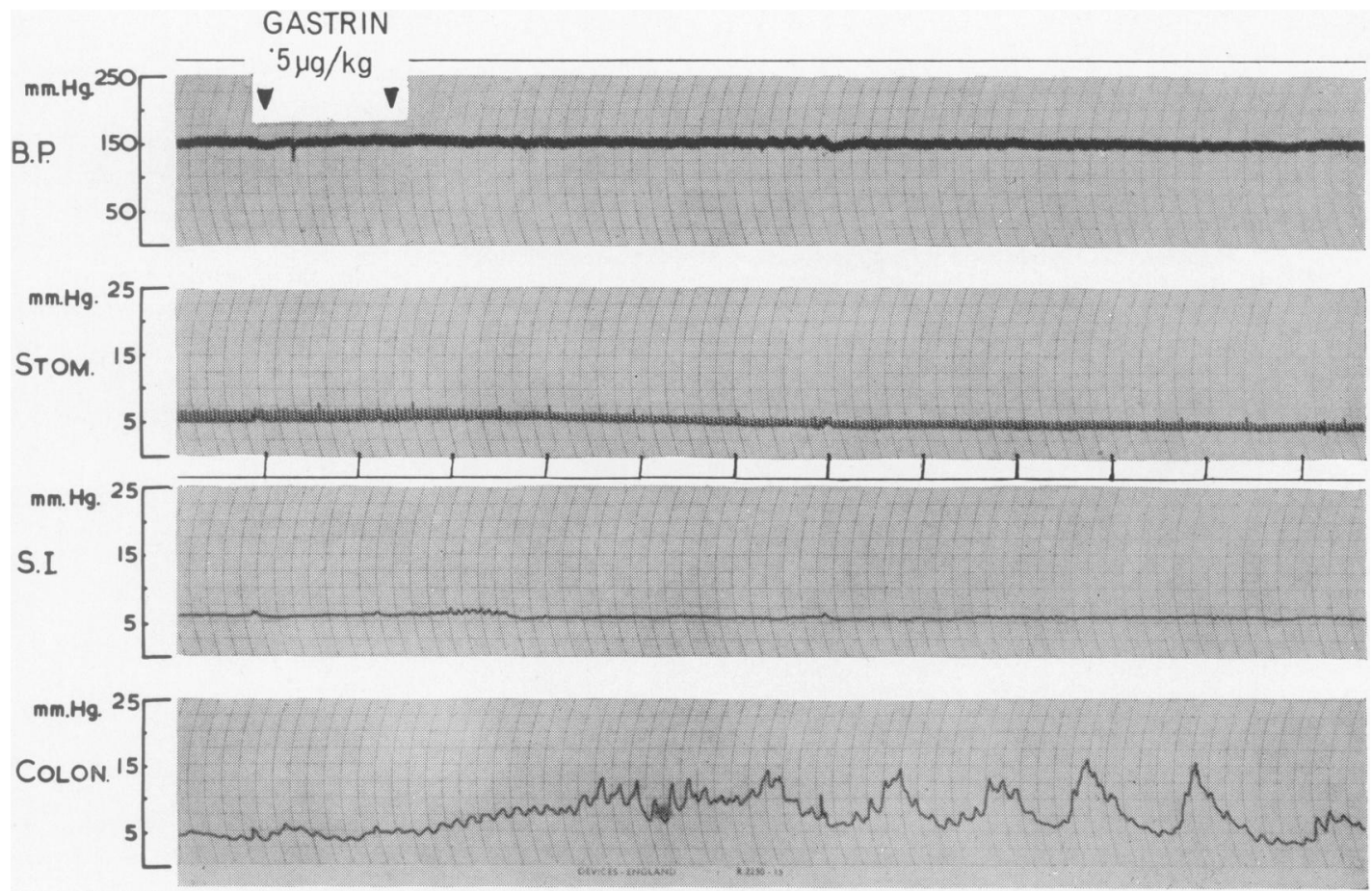

FIG. 1. The effect of gastrin on gut motility. Motility effects are shown in the small intestine and colon. Time signal in minutes. 
TABLE II

THE EFFECTS OF GASTRIN (LEO) ON GASTROINTESTINAL MOTILITY

\begin{tabular}{|c|c|c|c|c|}
\hline & $\begin{array}{l}\text { No. of } \\
\text { Experiments }\end{array}$ & Stomach & Small Intestine & Colon \\
\hline Initial preparation & 10 & $\begin{array}{l}\text { Slight increase in } 3 \\
\text { No effect in } 7\end{array}$ & $\begin{array}{l}\text { Moderate increase in } 3 \\
\text { Slight increase in } 4 \\
\text { No effect in } 3\end{array}$ & $\begin{array}{l}\text { Moderate increase in } 3 \\
\text { Slight increase in } 4 \\
\text { No effect in } 3\end{array}$ \\
\hline After $\alpha$-adrenergic blockade & 3 & No effect & $\begin{array}{l}\text { Marked increase in } 2 \\
\text { No effect in } 1\end{array}$ & $\begin{array}{l}\text { Marked increase in } 1 \\
\text { No effect in } 2\end{array}$ \\
\hline After $\beta$-adrenergic blockade & 4 & No effect & Slight increase in 3 & $\begin{array}{l}\text { Marked increase in } 1 \\
\text { Moderate increase in } 2\end{array}$ \\
\hline $\begin{array}{l}\text { After atropine } \\
\text { After atropine } \alpha \text { - and } \beta \text {-sympathetic } \\
\text { blockade }\end{array}$ & $\begin{array}{l}4 \\
7\end{array}$ & $\begin{array}{l}\text { No effect } \\
\text { Slight increase in } 4 \\
\text { No effect in } 3\end{array}$ & $\begin{array}{l}\text { No effect } \\
\text { Moderate increase in } 1 \\
\text { Slight increase in } 5 \\
\text { No effect in } 1\end{array}$ & $\begin{array}{l}\text { No effect } \\
\text { Moderate increase in } 3 \\
\text { Slight increase in } 3 \\
\text { No effect in } 1\end{array}$ \\
\hline
\end{tabular}

(Fig. 2). $\beta$-Adrenergic blockade increased the colonic effect of gastrin but the gastric and small intestinal actions were unaffected (Fig. 3). No effects on motility could be obtained with gastrin after atropinization of the animal unless both $\alpha$ and $\beta$ sympathetic blockade had been carried out. The results following both previously mentioned methods of sympathetic blockade were similar and these have therefore been combined for the purpose of analysis. In the presence of atropine and sympathetic blockade gastrin produced motility responses in the small intestine and colon (Fig. 4); the effect on the stomach was minimal. The motility effects of gastrin were unaffected by mepyramine.

I.C.I. 50,123 Experiments with this pentapeptide were performed in four cats and the results are summarized in Table III. In the initial preparation I.C.I. 50,123 was most effective in stimulating activity in the colon, the effect on the stomach and small intestine was slight (Fig. 5). In the atropinized animal the action of the pentapeptide on the colon was reduced but still definite (Fig. 6), there was a negligible effect on the motility of the stomach and

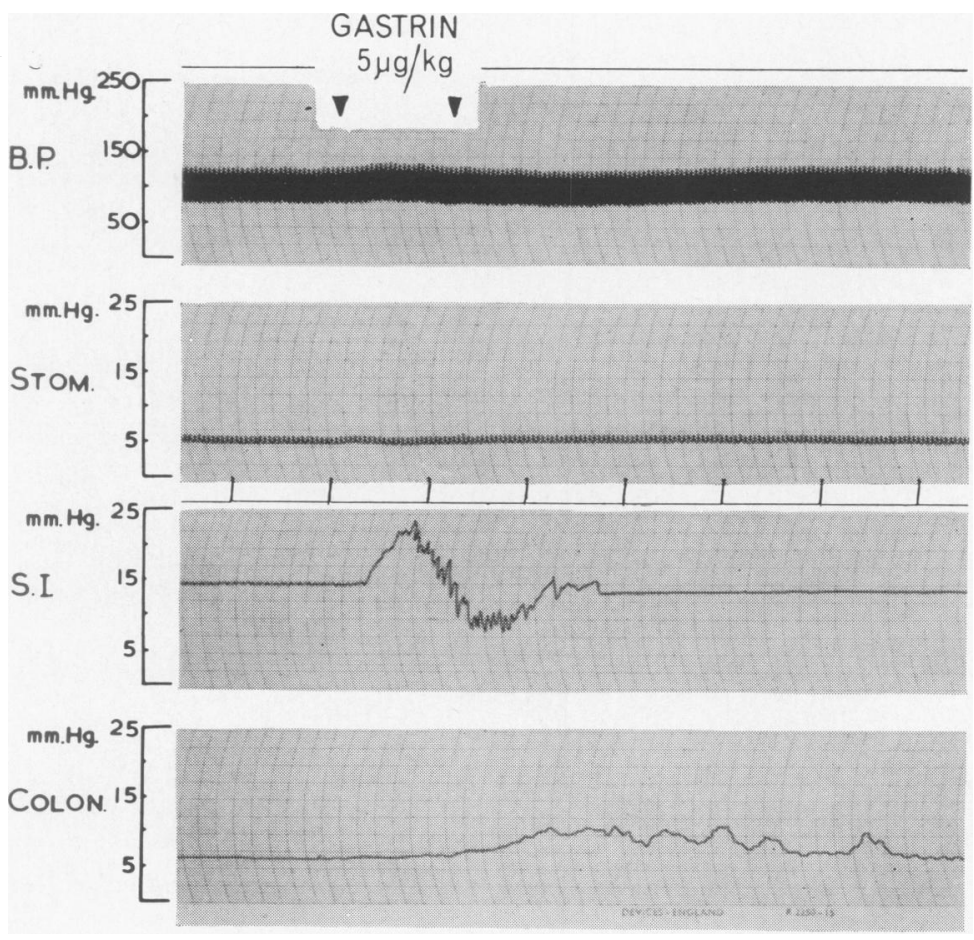

FIG. 2. The effect of gastrin on gut motility in a cat with $\alpha$-adrenergic blockade. The effect on the small intestine was potentiated. Time signal in minutes. 


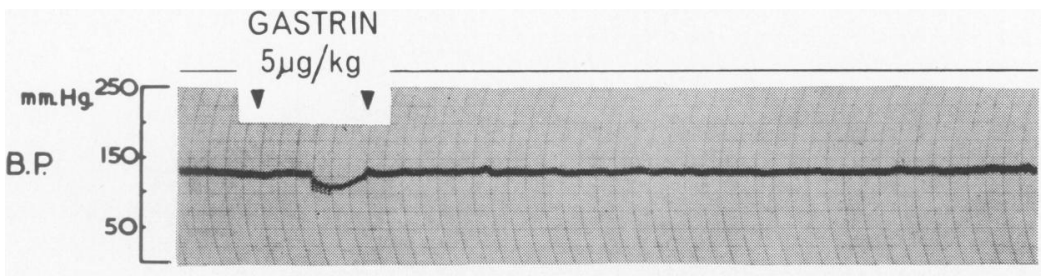

FIG. 3. The effect of gastrin on gut motility in a cat with $\beta$-adrenergic blockade. The effect on the colon was

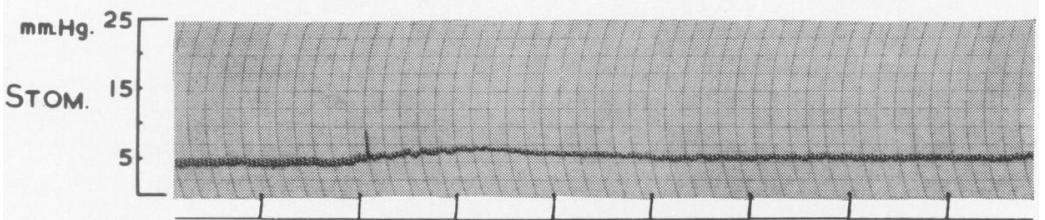
potentiated. Time signal in minutes.
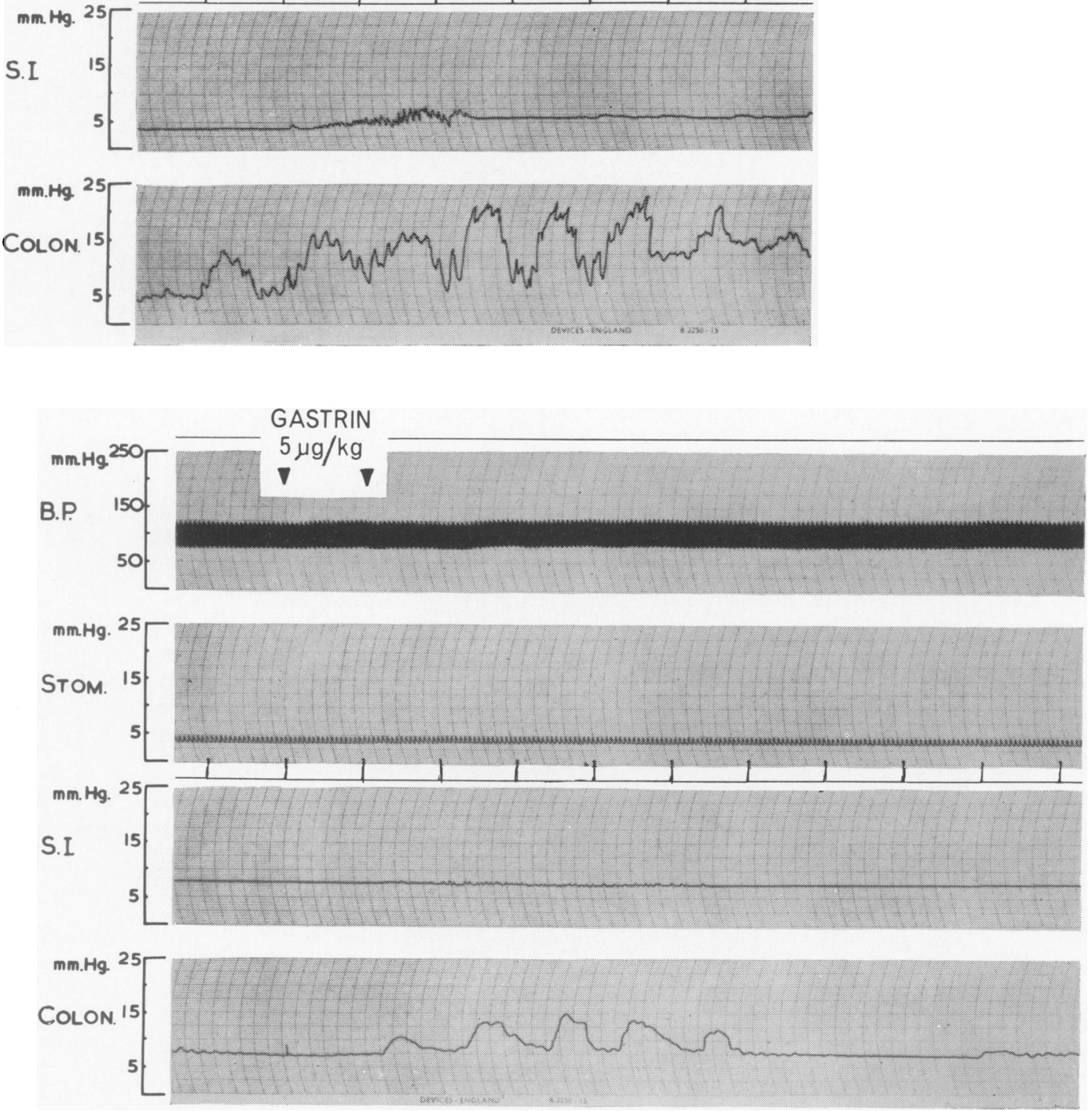

FIG. 4. The effect of gastrin on gut motility in the atropinized cat with sympathetic blockade. Motility effects are shown in the small intestine and colon. Time signal in minutes. 

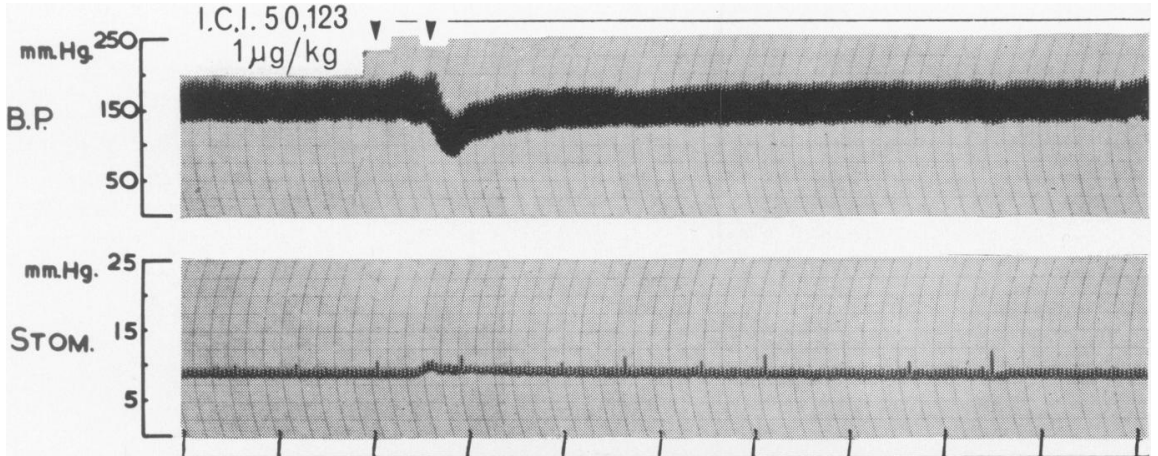

I.C.I. 50,123 on gut motility in the initial preparation. No activity was recorded from the small intestine but there was a marked colonic response. Time signal in

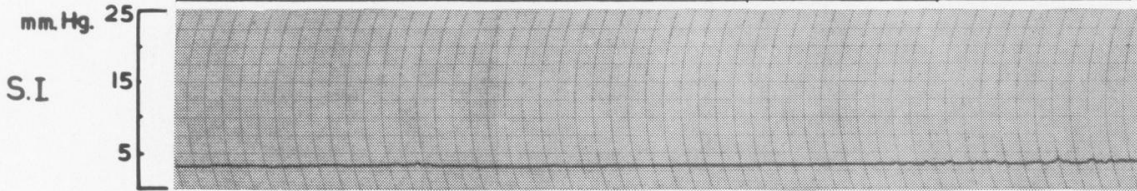
minutes.
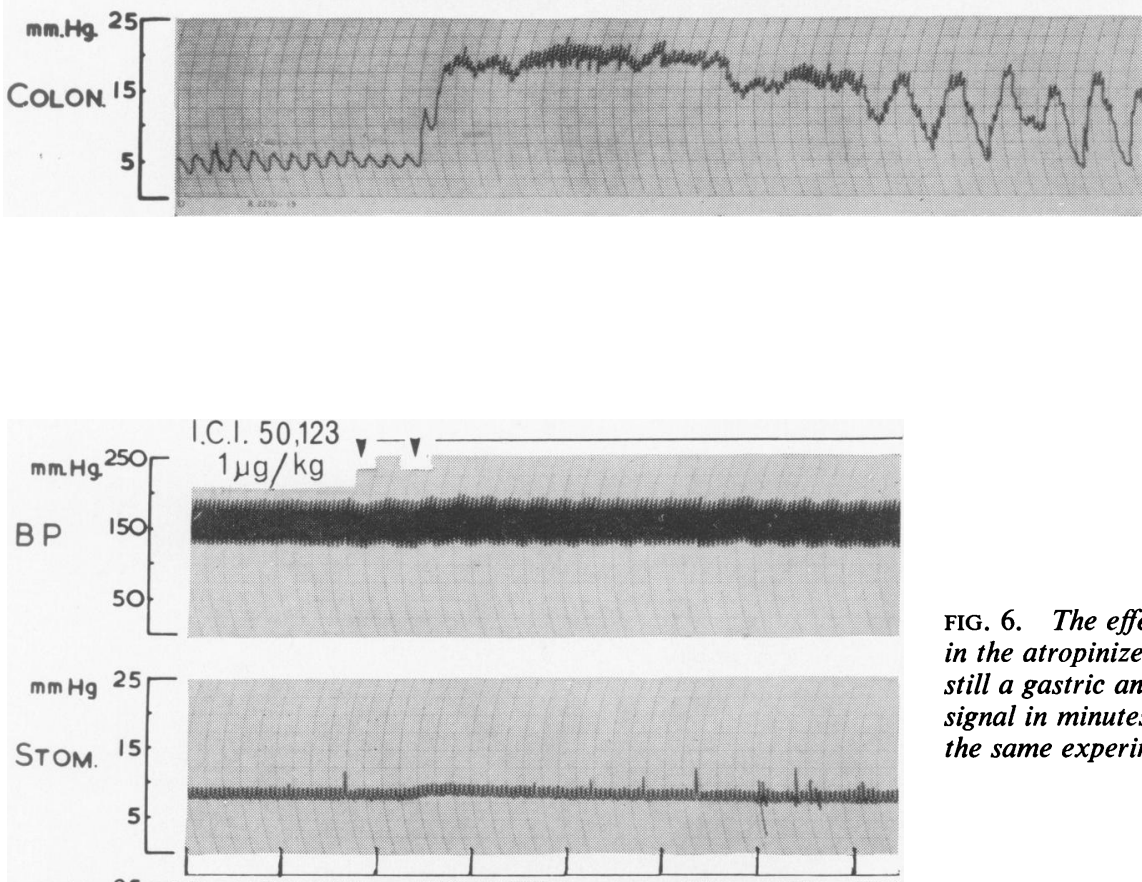

FIG. 6. The effect of I.C.I. 50,123 in the atropinized animal. There is still a gastric and colonic effect. Time signal in minutes. This tracing is from the same experiment as that in Figure 5.
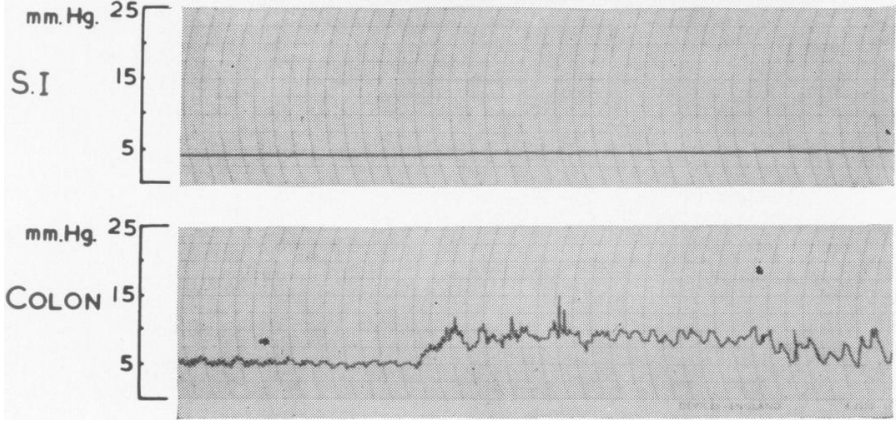
TABLE III

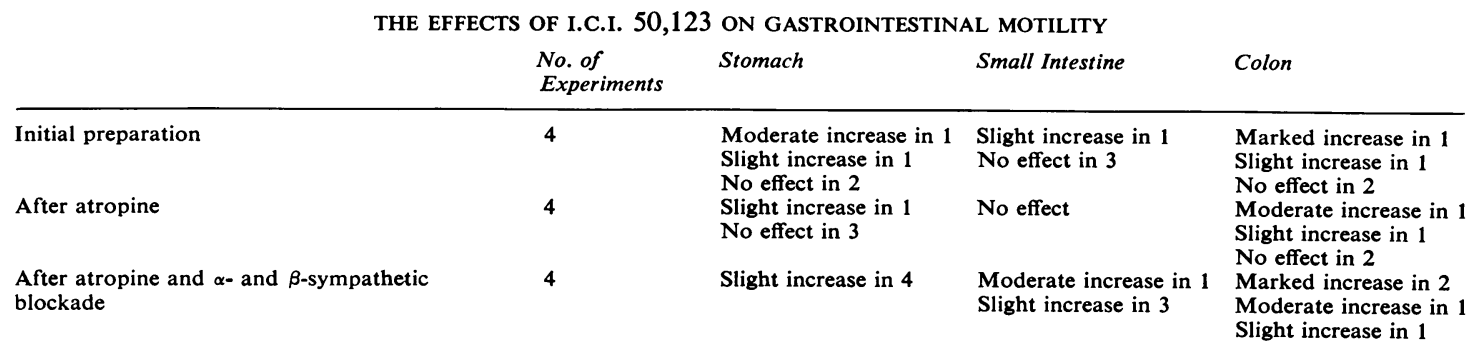

none on the small intestine. In the presence of atropine and $\alpha$ and $\beta$ sympathetic blockade the motility effect of the pentapeptide was increased in all three divisions of the gut, there being a marked increase in colonic motility and a smaller one in the stomach and small intestine.

Control injections of physiological saline were given in four animals with no motility responses. The volume of each infusion of gastrin or I.C.I. 50,123 was small, 1 to $2 \mathrm{ml}$, and spread over approximately one minute so it was unlikely that any injection artefacts were produced.

\section{DISCUSSION}

Early studies on the effects of gastrin on gastrointestinal motility by Blair and his colleagues (1961) showed that their extract produced a strong "pressor response' on the stomach and upper small intestine of anaesthetized cats. Similar results were obtained by Gregory and Tracy (1964) using gastrins I and II in conscious dogs. Bennett (1965) studied the effects of gastrin II on isolated strips of the stomach, small intestine, and colon of experimental animals and found that the most sensitive tissue was small intestine. The effects of gastrin II on motility of the gut in man have been examined by Smith and Hogg (1966) who found that the hormone had a readily demonstrable motor effect on the small intestine and colon. The study reported here has shown that in the anaesthetized cat gastrin has an approximately equal effect on the small intestine and colon, and a lesser effect on the stomach (Table II). The motility effect of the gastrin used in these experiments was unaffected by mepyramine and therefore was unlikely to have been due to contamination of the extract with histamine.

When Tracy and Gregory (1964) studied the physiologically active gastrin-like peptides on the conscious dog they found that the gastric motility response was slightly different from that obtained with natural gastrin and that the small intestine motility effect was variable. Logan and Connell (1966) could not demonstrate a significant motility effect on the small intestine of man with I.C.I. 50,123 but they obtained a marked colonic effect. Using I.C.I. 50,123 in the anaesthetized cat we obtained a significant motility response in the stomach and colon but only a minimal response in the small intestine. It appears, therefore, that there may be some difference in the spectrum of action of natural gastrin and the synthetic pentapeptide as far as their motility effects are concerned.

Bennett (1965) has suggested that gastrin acts by releasing acetylcholine from post-ganglionic parasympathetic nerves. He found that the motility responses of preparations in vitro were reduced or abolished by hyoscine and similar results have been obtained from experiments in vivo (Gregory and Tracy, 1964; Logan and Connell, 1966). No studies of atropine on the motility effects of the synthetic pentapeptide have been published. In the present study no motility was obtained with gastrin in the atropinized animal (Table II) but a significant, though reduced, effect was obtained with I.C.I. 50,123 (Table III and Fig. 6). However, an effect with gastrin could always be obtained in the atropinized animal following sympathetic blockade (Table II). There may thus be a slight difference in the mode of action of gastrin and I.C.I. 50,123 and gastrin does not appear to act in the cat by releasing acetylcholine; this latter point is supported by the findings of Blair et al. (1961).

Table II shows that $\alpha$-adrenergic blockade potentiated the effect of gastrin on the small intestine and that $\beta$-adrenergic blockade potentiated its effect on the colon. This supports the hypothesis that $\alpha$-adrenergic receptors predominate in the small intestine and $\beta$-adrenergic receptors predominate in the colon (Neely and Catchpole, 1967).

\section{SUMMARY}

A study has been made of the effects of gastrin (Leo) and the synthetic pentapeptide I.C.I. 50,123 on the motility of the stomach, small intestine, and colon of the anaesthetized cat. Gastrin produced motility effects in the small intestine and colon but I.C.I. 
50,123 failed to produce a motility response in the small intestine. The effect of atropine on the actions of these two substances also differed.

It is suggested that there is a difference both in the spectrum and mode of action of gastrin and I.C.I. 50,123 on gut motility.

Miss Diana Aitken supplied invaluable technical help and Dr. J. D. Fitzgerald of the Pharmaceuticals Division of the Imperial Chemical Industries kindly provided the I.C.I. 50,123. This work was supported by a grant from the Joint Research Board of St. Bartholomew's Hospital. Thanks are due to Professor G. W. Taylor and Mr. B. N. Catchpole for their advice and encouragement.

\section{REFERENCES}

Bennett, A. (1965). Effect of gastrin on isolated smooth muscle preparation. Nature (Lond.), 208, 170-173.
Blair, E. L., Harper, A. A., Lake, H. J., Reed, J. D., and Scratcherd, T. (1961). A simple method of preparing gastrin. J. Physiol. (Lond.), 156, 11-12P.

Gregory, R. A., and Tracy, H. J. (1959). The preparation and properties of gastrin. Ibid., 149, 70-71P.

- (1964). The constitution and properties of two gastrins extracted from hog antral mucosa. Gut, 5, 103-117.

Koelle, G. B. (1965) Neurohumoral transmission and the autonomic nervous system. In Pharmacological Basis of Therapeutics edited by L. S. Goodman and A. Gilman, 3rd Ed., p. 403. Macmillan, New York.

Logan, C. J. H., and Connell. A. M. (1966) The effect of a synthetic gastrin-like pentapeptide (I.C.I. 50, 123) on intestinal motility in man. Lancet, 1, 996-999.

Neely, J. A. C., and Catchpole, B. N. (1967). An analysls of the autonomic control of gastrointestinal motility in the cat, Gut, 8, 242-248.

Smith, A. N., and Hogg, D. (1966) Effect of Gastrin II on the motility of the gastrointestinal tract. Lancet, 1, 403-404.

Tracy, H. J., and Gregory, R. A. (1964). Physiological properties of a series of synthetic peptides structually related to Gastrin $I$. Nature (Lond.), 204, 935-938.

\section{政}

